\title{
EDITORIAL
}

\section{In This Issue: Different Paths to Discovery}

\author{
Kurt C. Stange, $M D, P b D$, Editor \\ Ann Fam Med 2016;14:398-399. doi: 10.1370/afm.1985.
}

$\mathrm{T}$ This issue of Annals shows different paths to discern relevant evidence for understanding and improving health and health care. Ways of discovery in this issue include: experimentation ${ }^{1,2}$ and systematic synthesis of experimental evidence ${ }^{3}$; simulations of process and outcomes of policy interventions ${ }^{4}$; comparison of complementary perspectives ${ }^{5,6}{ }_{i}$, careful longitudinal observation ${ }^{7-9} ;$ reflective witnessing ${ }^{10-12}$; and readers' shared experiences and reflections ${ }^{15}$

Two clinical trials provide experimental evidence against treatments that had shown promise in prior observational studies and small clinical trials. Smith et al test the hypothesis that asthmatic people who attempt to take probiotics daily might reduce respiratory infections, asthma exacerbations, or antibiotic use. They do not. ' Souwer et al test the hypothesis that the vascularly active drug nifedipine can reduce the symptoms of chilblains - the painful inflammation of small blood vessels in response to exposure to cold. It does not. ${ }^{2}$

In contrast, a systematic synthesis of evidence from multiple clinical trials shows that several psychological interventions for postnatal depression are effective in primary care, both immediately and in up to 6 months of follow-up. The positive effects include not only depressive symptoms, but adjustment to parenthood, marital relationship, social support, and reduction in stress and anxiety. ${ }^{3}$

A different kind of evidence synthesis and experimentation is pursued by Basu and colleagues, who created a simulation model to test net practice revenue and service delivery in 3 approaches to funding the patientcentered medical home. They find that different financial incentives have a strong effect, and the beneficial effects of per-member per-month payment at current levels may be limited for expanding services beyond minimum patient-centered medical home requirements, due to the opportunity costs of lost fee-for-service revenue. ${ }^{4}$ An insightful editorial by Magill puts this work into the larger context of how to pay for primary care. ${ }^{5}$

Two other research articles provide new insights by comparing complementary perspectives. Tran et al compare patient and physician perspectives on the importance of different drugs and patients' adher- ence to taking the drugs. They find limited correlations between physician and patient reports of drug adherence or importance, and no association between physicians' assessment of drug importance and patient reports of their drug adherence. ${ }^{6}$ Behar and col-

leagues examine reported experiences of patients who have been prescribed opioids and the possibilities of co-prescription of naloxone for use in immediate treatment of accidental overdose. Co-prescription of naloxone with opioids is endorsed by $97 \%$ of patients. ${ }^{7}$

Two studies presented in this issue provide insights from careful longitudinal observation. In cohorts of children seen in primary care and children referred to a specialist, Holtman and colleagues examine the diagnostic accuracy of fecal calprotectin as a noninvasive diagnostic test for inflammatory bowel disease in children with chronic diarrhea and/or recurrent abdominal pain. With a high negative predictive value, a negative fecal calprotectin appears to be useful in ruling out inflammatory bowel disease in children with chronic gastrointestinal symptoms. ${ }^{8}$

Brooks uses a different kind of longitudinal observation-oral histories of 52 primary care physicians-and discovers 5 decades of discouragement and disparagement about primary care. This results in ongoing hostility toward primary care through the culture and structure of medical training. ${ }^{9}$

The effects of mental illness in individuals, families, and clinicians is powerfully brought to light by the witness of 3 insightful and reflective observers who bring together multiple points of view. A mental health professional and educator observes how family physicians are positioned to intervene in powerful ways to support mentally ill people and their families. ${ }^{10} \mathrm{~A}$ daughter shares her experience of the effect of her father's bipolar disorder on their relationship, and reflects on how her relationship with her father might have been different if she had learned effective coping strategies from her family physician. ${ }^{11}$ In the third essay, a physician shares a patient's anxiety that the mental illness affecting the patient's siblings will touch her as well. ${ }^{12}$ An editorial by deGruy and Green draws lessons that link policy and practice. ${ }^{13}$ 
Another way of discovery is the thoughtful reflections of readers based on their experience and other knowledge, generously shared through the Annals TRACK online discussion. ${ }^{14}$ We welcome your reflections at http://www.AnnFamMed.org.

\section{References}

1. Smith TDH, Watt H, Gunn L, Car J, Boyle R. Recommending oral probiotics to reduce winter antibiotic prescriptions in people with asthma: a pragmatic randomized controlled trial. Ann Fam Med. 2016;14(5):422-430.

2. Souwer IH, Bor JHJ, Smits P, Lagro-Janssen ALM. Nifedipine vs placebo for treatment of chronic chilblains: a randomized controlled trial. Ann Fam Med. 2016;14(5):453-459.

3. Ford E, Paudyal P, Smith H, Stephens S. Effectiveness of psychological interventions for postnatal depression in primary care: a metaanalysis. Ann Fam Med. 2016;14(5):463-472.

4. Basu S, Phillips RS, Song Z, Landon BE, Bitton A. Effects of new funding models for patient-centered medical homes on primary care practice finances and services: results of a microsimulation model. Ann Fam Med. 2016;14(5):404-414.

5. Magill MK. Time to do the right thing: end fee-for-service for primary care. Ann Fam Med. 2016;14(5):400-401.
6. Sidorkiewicz S, Tran V, Cousyn C, Perrodeau E, Ravaud P. Discordance between drug adherence as reported by patients and drug importance as assessed by physicians. Ann Fam Med. 2016;14(5):415-421.

7. Behar E, Rowe C, Santos G, Murphy S, Coffin PO. Primary care patient experience with naloxone prescription. Ann Fam Med. 2016;14(5):431-436.

8. Holtman GA, Lisman-van Leeuwen Y, Kollen BJ, et al. Diagnostic accuracy of fecal calprotectin for pediatric inflammatory bowel disease in primary care: a prospective cohort study. Ann Fam Med. 2016;14(5):437-445.

9. Brooks J. Hostility during training: historical roots of primary care disparagement. Ann Fam Med. 2016;14(5):446-452.

10. McBride JL. Family physician support for a family with a mentally ill member. Ann Fam Med. 2016;14(5):460-462.

11. Kahre S. Bipolar disorder: A daughter's experience. Ann Fam Med. 2016;14(5):473-474.

12. Kannai R, Alon A. Hope. Ann Fam Med. 2016;14(5):475-477.

13. deGruy FV, Green LA. Return, for good this time, to practicing in the context of families and communities. Ann Fam Med. 2016;14(5):402-403.

14. Stange KC. On TRACK: How to use the Annals online discussion. Ann Fam Med. 2004;2(6):611-612.

\section{CORRECTIONS}

Ann Fam Med 2016;14:399. doi: 10.1370/afm.1989.

In: Stange KC. Possible unintended consequence of an evidence-based clinical policy change [Annals Journal Club]. Ann Fam Med. 2015;13(4):iii, the author's middle initial is listed as $\mathrm{S}$ instead of $\mathrm{C}$. We deeply regret this error.

Ann Fam Med 2016;14:399. doi: 10.1370/afm.1990.

In: Knottnerus BJ, Geerlings SE, Moll van Charante EP, ter Riet G. Toward a simple diagnostic index for acute uncomplicated urinary tract infections. Ann Fam Med. 2013;11(5):442-451, the author discovered errors:

Table 1

- "Pain during micturition", category "No" left column: 35 should be 36

Table 2

- "Nitrite positive", category "Yes", left column: 62 should be 63

- "Sediment", "Bacteria", category "Few", 3rd column: 17 should be 21

Tables 2 and 3

- "Nitrate" should be "Nitrite"

Figure 1

- Column "History", numbers under middle box: 0.81 (0.72-0.88) should be 0.59 (0.48-0.68)

- Column "History", numbers under lower box: 0.81 (0.72-0.88) should be 0.14 (0.06-0.31)

- Column "History Dipstick", numbers under middle box: 0.95 (0.87-0.98) should be 0.65 (0.52-0.77)

- Column "History Dipstick", numbers under lower box: 0.95 (0.87-0.98) should be 0.21 (0.13-0.32)

- Column "History Dipstick Sediment", numbers under middle box: 0.91 (0.84-0.95) should be 0.64 (0.47-0.78)

- Column "History Dipstick Sediment", numbers under lower box: 0.91 (0.84-0.95) should be 0.13 (0.07-0.23)

- Column "History Dipstick Sediment Dipslide", numbers under middle box: 0.96 (0.90-0.98) should be $0.66(0.48-0.80)$

- Column "History Dipstick Sediment Dipslide", numbers under lower box: 0.96 (0.90-0.98) should be $0.12(0.06-0.21)$

\section{Figure 2A}

- Column "History", numbers under middle box: 0.81 (0.72-0.88) should be 0.59 (0.48-0.68)

- Column "History", numbers under lower box: $0.81(0.72-0.88)$ should be $0.14(0.06-0.31)$

Figure 2B

- Column "History", numbers under middle box: 0.81 (0.72-0.88) should be 0.59 (0.48-0.68)

- Column "History", numbers under lower box: 0.81 (0.72-0.88) should be 0.14 (0.06-0.31)

- Column "History Dipstick Dipslide", numbers under upper box: 0.81 (0.73-0.87) should be 0.86 (0.79-0.91)

The author regrets the errors. New tables and figures have been uploaded to AnnFamMed.org. The online version of the article therefore differs from the print. 